\title{
Investigation of Mammoth Tusks from the Paleolithic Sites of the European Part of Russia by the IR Reflection Spectroscopy
}

\section{Zolotarev VM${ }^{1 *}$ and Khlopachev GA ${ }^{2}$ \\ ${ }^{1}$ St. Petersburg National Research University of Information Technologies, Mechanics, and Optics, Russia}

${ }^{2}$ Peter the Great Museum of Anthropology and Ethnography, Russian Academy of Sciences, Russia

Submission: December 04, 2018; Published: December 13, 2018

*Corresponding author: Zolotareva VM, St. Petersburg National Research University of Information Technologies, Mechanics, and Optics, St. Petersburg, Russia

\section{Abstract}

Based on the optical model of a porous rough surface typical of archeological and paleontological objects, the mathematical processing of the infrared (IR) reflection spectra of such objects was performed and the frequencies in the IR reflection spectra of objects with a rough surface were identified. Examples of research by the non-destructive method of IR spectra of mirror reflection of mammoth tusks from two Paleolithic sites $(14,000$ and 16,000 BC), pos. Yudinovo, Bryansk region, Russia. The results are compared with traditional methods of diffuse infrared reflection and the $\mathrm{KBr}$ technique.

Keywords: IR reflection spectroscopy; Mammoth tusks

\section{Introduction}

Objects of archeology and paleontology are mainly investigated using the destructive method of the $\mathrm{KBr}$ technique or diffuse IR reflection. In some cases, when the question concerns the study of objects of a sacral nature, this technique cannot be used. A possible way out of this situation is the use of the method of mirror IR reflection. However, the uneven and rough surface of real objects complicates the mathematical processing of such measurements.

In [1], an optical model of the rough surface of a real object typical of archeology and paleontology [2,3] was considered. To implement this model, data on the optical properties of the object in the IR spectral region are needed. Since the basis of objects (fragments of mammoth tusks) of paleontology includes the mineral apatite $\mathrm{Ca}_{5}\left(\mathrm{PO}_{4}\right)_{3}(\mathrm{OH})$, its spectral absorption characteristics were determined in the range of 6-28 microns [4]. This made it possible to correctly process the IR spectra of the specular reflection of several objects (fragments of mammoth tusks) [1]. In [5] a comparison was made of the sensitivity of nondestructive methods of specular and diffuse reflection. In the latter method, the sample was prepared in two ways [5-8].

a. Was ground into a fine powder and placed in transparent immersion medium.

b. Was investigated in the mode of in situ.

\section{Research Results}

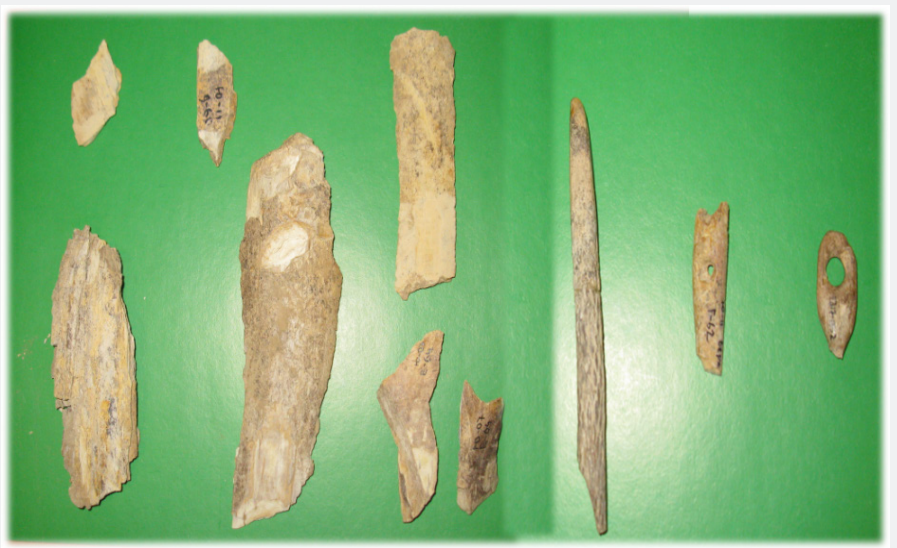

Figure 1: Fragments of mammoth tusks. On the right side of the figure, three artifacts are made and mammoth tusks. 


\section{Global Journal of Archaeology \& Anthropology}

Objects of investigation [1] were obtained from the holdings of the Museum of Anthropology and Ethnography of the Russian Academy of Sciences. The specimens were predominantly slivers split off from mammoth tusks used in household activities of ancient people and artifacts (Figure 1) decorated with carved rhombic ornaments, which were found upon excavation at two paleolithic sites that are situated in Yudinovo (Bryansk oblast, Russia). The sites are from two different archeological time periods and have similar lithic industries of bone processing; at each of them, a vast collection of stone and bone implements was excavated, especially artifacts made of mammoth tusks, which were used for making hunting weapons, navy tools, decorations, and other household needs [2,3]. The multiplicity and diversity of tusk implements from the Yudinovo sites and their good preservation and assignments to different chronological habitation levels of ancient people create a good basis for verification and subsequent application of nondestructive IR reflection spectroscopy methods to the solution of a series of archeological problems related with climatic habitation conditions, as well as with the sedentism and duration of occupation of paleolithic sites.

Main conclusion
It is generally accepted to divide specimens of mammoth tusks found in archeological excavations into three groups differing in the conditions under which they were found. Specimens of the first group were found on the "daytime" surface of the site, specimens of the second group were found inside "dwellings," and specimens of the third group were concealed in "household" pits of different designations. Most specimens chosen for investigation belong to the first group. These specimens are bent split plates of mammoth tusk of a cylindrical shape. All the specimens found were cleaned from soil and sediments with brush, washed with fresh water, and dried. Dating for the upper (14000 BCE) and lower (16000 BCE) paleolithic sites, which were located at horizons of 2 and $4 \mathrm{~m}$ from the ground surface, respectively, was performed with carbon ${ }^{14} \mathrm{C}$ radioisotope analysis. For comparison, radioisotope analysis was also performed for pieces that were cut from whole mammoth tusks that were obtained from Eastern Siberia (Yakutia), which are used in restoration works and which were in a very good condition upon visual examination and had a whitish light-yellow cream-colored hue (which is an indication of good preservation of the object.

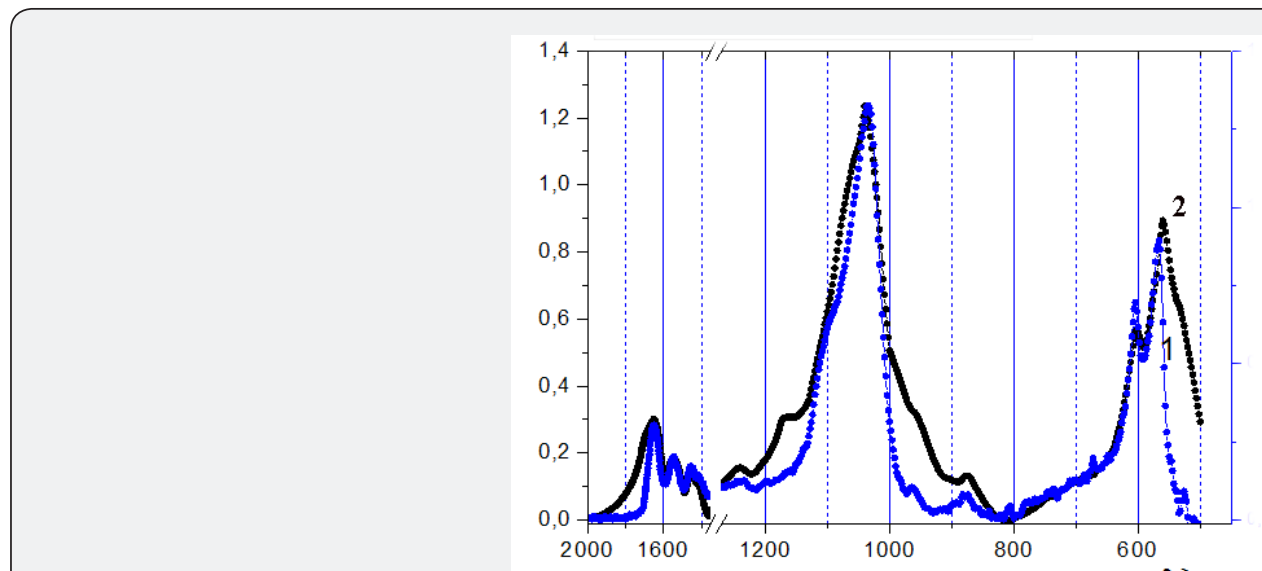

Figure 2: Absorption spectra obtained for the mammoth tusk in non-polarized radiation: 1- (Kramers-Kronig method). 2- technology KBr.

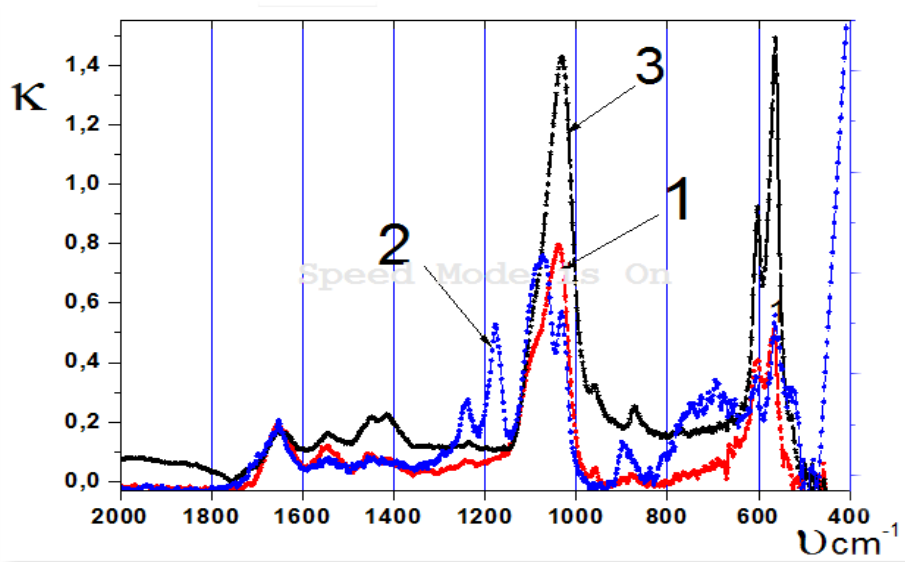

Figure 3: Absorption spectra (calculated by the Kramers-Kronig method) for a mammoth tusk (rough surface) in polarized radiation. 1 -vector $E$ of radiation perpendicular to the axis of the tusk, 2-vector E parallel to the axis of the tusk, 3- spectrum of the tusk of the elephant (smooth surface). 
In generalizing the results of application of the IR reflection spectroscopy method to the investigation of mineralization process of mammoth tusks, we should note that the optical model of a porous surface that was proposed in the first part of this work forms guidelines for correct mathematical processing of spectra, which makes it possible to extract reliable data on frequencies in the vibrational spectrum of the object. Figure 2 shows a comparison of the normalized absorption spectra for a fragment of a mammoth's tusk, obtained by the traditional $\mathrm{KBr}$ (powder) method and specular reflection without disturbing the surface (method Kramers-Kronig). Useful information can be obtained from the analysis of the spectra of oriented tusk fragments in polarized radiation (Figure 3).

Useful information Figure 4 can be obtained from the analysis of the spectra of fragments from the location of the fragment and from its location on this site. The sample is oriented relative to the surface of the earth. The side of the fragment that is in contact with the ground is internal, and the opposite side is external. It follows from our studies of the IR reflection spectra of mammoth tusks that the specimens of the first group are characterized by only one basic mineralization process [9]. This process proceeds both in the volume and, more actively, on the surface of the specimen. Taking into account that, in accordance with the IR spectroscopy data, the content of $\mathrm{CaCO}_{3}$ in the specimens of the first group from the upper layer of the soil is, on average, higher than in the lower layer and taking into account mineralization processes strongly depend on the temperature, humidity, and concentration of $\mathrm{CO}_{2}$ of the Earth's atmosphere, it follows from these investigations that the above listed external factors noticeably increased in magnitude during the time of existence of the upper site of ancient people.

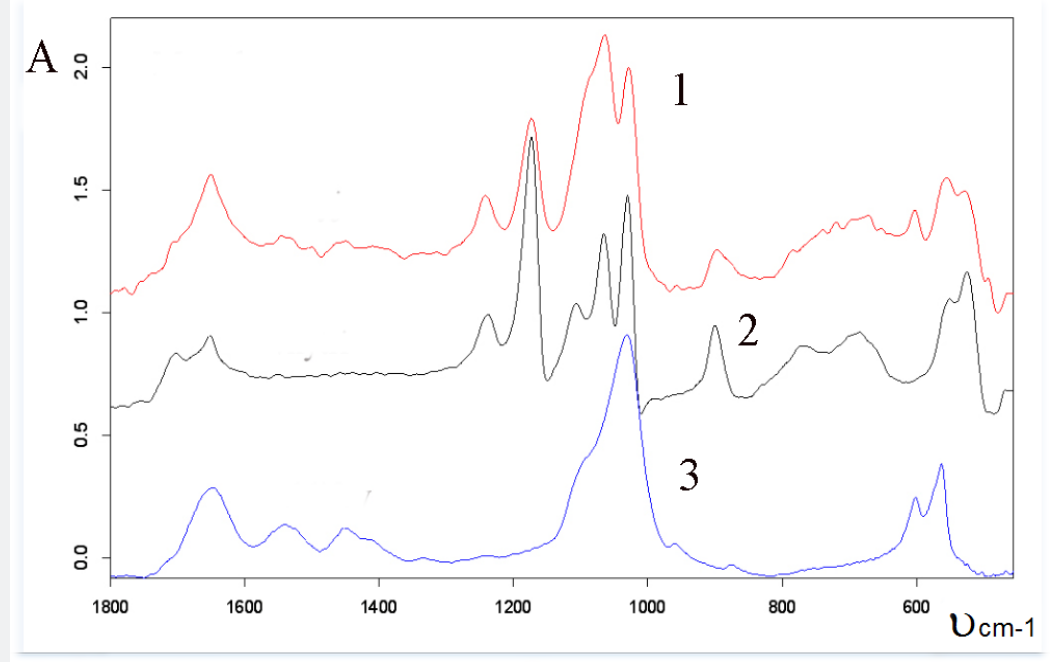

Figure 4: Absorption spectra for a mammoth tusk fragment: 1- tusk surface (facing up) 2-surface (lying on the ground), 3-inner part of a tusk fragment (obtained as a result of polishing).

These conclusions correlate well with results of geophysical investigations [10], which indicate that, in the period of existence of the lower and upper paleolithic sites (Yudinovo, Bryansk oblast, Russia), there occurred an increase in the temperature of the surface of the Earth and, correspondingly, in the humidity, as well as in the concentration of $\mathrm{CO}_{2}$ in the Earth's atmosphere. For specimens of the third group, the first stage of mineralization is supplemented by the bioprocess, which proceeds only on the surface. The competition between these two processes of destruction of mammoth tusks depends on the biochemical conditions experienced by the specimen at the initial period, because these conditions determine the biological activity of microorganisms involved in assimilation of compounds of the surface layer.

Considering that the time period during which the bio destruction proceeds is comparatively short compared to the entire time of burial of the object in the ground, the IR spectrum allows one to obtain information on the conditions of the bio destruction stage, which is tied to the radiocarbon time mark. In conclusion, we can state that the proposed optical model for the description of the IR reflection spectra of bones makes it possible to process in situ the spectra of real objects with nonfat and rough surfaces. It is significant that the properties of the volume and surface of bones can be very different, which yields additional information on external and local factors that affect mineralization processes in specimens for different time conditions, which, in particular, were realized for the upper and lower paleolithic sites at Yudinovo. For spectroscopic studies of objects from different archeological layers, it is expedient to additionally classify objects according to the conditions of their orientation with respect to the ground surface upon excavation and to indicate the ground water level in places of their discovery in the legend of specimens.

\section{References}

1. Zolotarev VM, Khlopachev GA (2013) Optics and Spectroscopy. 114(6): 946-960.

2. Khlopachev GA (2006) Tusk Industries of the Upper Paleolith of the Eastern Europe.

3. Khlopachev GA (2011) Armament Supplies and Objects of Art Made of Bone in Ancient Cultures of the Nothern Eurasia.

4. Zolotarev VM (2018) Optics and Spectroscopy. 124(2): 262-272. 
5. Zolotarev VM (2014) Optics and Spectroscopy. 116(4): 599-613.

6. Griffiths PR (2007) Fourier Transform Infrared Spectrometry.

7. Derrick MR, Stulik D, Landry JM (1999) Infrared Spectroscopy in Conservation Science. The Getty Conservation Institute, Los Angeles, USA.

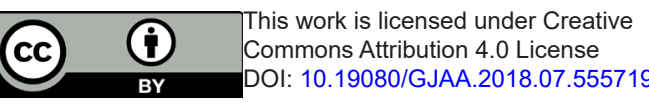

8. Rein A, Higgins F (2011) Handheld FTIR Analysis for the Conservation and Restoration of Fine Art and Historical Objects.

9. Turner Walker G (2008) In Advances in Human Palaeopathology, Pinhasi R, Mays S (Eds.), New York, USA, p. 1-29.

10. Petit JR, Jouzel J, Raynaud D (1999) Nature 399: 429.

\section{Your next submission with Juniper Publishers will reach you the below assets}

- Quality Editorial service

- Swift Peer Review

- Reprints availability

- E-prints Service

- Manuscript Podcast for convenient understanding

- Global attainment for your research

- Manuscript accessibility in different formats

( Pdf, E-pub, Full Text, Audio)

- Unceasing customer service

Track the below URL for one-step submission https://juniperpublishers.com/online-submission.php 